\title{
Mad Men as a Sonic Symptomatology of Consumer Capitalism
}

\author{
By Marc Brooks*
}

AT THE HEIGHT OF THE BRITISH INVASION in 1966, after a client insists on having a band that at least sounds like the Beatles in their advert, Don Draper wonders: 'When did music become so important?? ${ }^{21}$ Don is talking about youth culture, from which he feels increasingly distant. But music also became 'so important' in television advertising during the 1960s, when Mad Men (Matthew Weiner, AMC 2007-15) is set, because advertisers were relying ever more on affect. ${ }^{2}$ Don-the implausibly handsome, successful, and yet curiously dissatisfied creative director of a middling Madison Avenue advertising company around whom the show revolves—sums up the situation nicely to his young protégée Peggy Olsen: 'You are the product. You feeling something. That's what sells'. ${ }^{3}$ Music, advertisers came to realize, is particularly good at making viewers feel things. ${ }^{4}$

Unlike The Sopranos (1999-2007), The Wire (2002-08), and Battlestar Galactica (2004-09), which are generally held to deserve the epithet 'quality TV', Mad Men splits critics down the middle. ${ }^{5}$ One of the main complaints is that it assumes the form of its subject matter; it offers

*University of Vienna. Email: Marc.Brooks@outlook.at. This article is based on talks given at the 'Intertextuality in Music since 1900' conference at the Universidade Nova de Lisboa, 6-7 March 2015, and at the 15th Annual Conference of the Society for Musicology in Ireland at Queen's University Belfast, 16-18 June 2017. I would like to thank the participants at these conferences for their stimulating points, comments, and criticisms, many of which have been incorporated into the final draft. I am also grateful to the reviewers and editorial staff at Music \& Letters for their invaluable support.

1 'Lady Lazarus' (season 5, episode 6; originally aired in the US on 6 May 2012).

${ }^{2}$ Although affect and musical affect had of course been exploited before, advertising executives did not become explicitly interested in the affective qualities of music until the very late 1950s. This was partly due to television, but a number of other important factors were also at play. See Chapter 4 of Timothy D. Taylor, The Sounds of Capitalism: Advertising, Music, and the Conquest of Culture (Chicago, 2012), 101-25.

3 'For Those who Think Young' (S2, E1; 27 July 2008).

${ }^{4}$ Advertisers and advert composers often talk in this period about 'emotion' and music's ability to emotionally manipulate viewers. But this is only because they are using the word 'emotion' for every experience that isn't 'intellectual'. If you look at how they describe and use music, it is clear that they mean something much broader, which is better covered by 'feeling' or 'affect'. Again see Chapter 4 of Taylor, Sounds of Capitalism.

${ }^{5}$ Note that the scholarly use of 'quality TV' already includes the critique that the 'golden age of television' that we are supposedly enjoying at the moment is largely a marketing strategy developed by television companies to exploit the particular complex of broadcast deregulation, proliferation of viewing platforms, subscription models of cable companies, audience fragmentation, and other currently prevailing material conditions, and is not a value judgement about the actual 'quality' of the shows. See the essays collected in Janet McCabe and Kim Akass (eds), Quality TV: Contemporary American Television and Beyond (London, 2007). 
the same meretricious pleasure as the modern affective advert-atmosphere, emotion, sensuality. Mark Greif calls this 'Now Doesn't That Look Good' TV, which includes the meticulously reconstructed and lovingly filmed 1960s furniture, outfits, and other consumer products. ${ }^{6}$ But 'Now Doesn't that Look Good' would be blandly incorporeal without a corresponding 'Now Doesn't that Sound Good'. The satisfying metallic clunk of Don's Zippo, the mouth-watering clatter of ice cubes in the solid curved whiskey tumblers, the creak of new car leather all help to figure a sensuous world more enticing than reality. In a similar vein, the carefully curated contemporaneous soundtrack acts as sonic wallpaper animating the period mise-en-scene.

But music becomes particularly 'important' in the vignettes that most obviously resemble contemporary advertising. Consider the opening montage of 'Maidenform' (S2, E6; 31 August 2008), an episode set in motion by Playtex executives who want to ditch their safe, conservative image for something more like Maidenform's racy 'I dreamed' campaign. The forceful groove of The Decembrist's 'The Infanta' (2005- a rare use of an anachronistic song) plays over images of the three main female cast members dressing in the morning. The visuals capture their individual personalities, but the pounding drums and driving guitar transforms them into warriors donning chainmail to protect themselves from the onslaught of sexism they'll face that day. The vintage undergarments don't just look good, they sound-and hence feel-good. Greif would be right to object that, whichever way you cut it, pictures of attractive women in bras are still being used to sell—in this case the programme itself. Nevertheless, the montage effectively parodies the contemporary quasi-feminist advert which promises that the product will restore to women the very confidence and self-esteem that the commoditization of their bodies has already done so much to remove.

Such parodies are not the only way in which pre-existing music is used critically in the show. Tim Anderson has shown that songs in Mad Men often act as 'critical interlocutors that act as a counterpoint to onscreen imagery'; that is, the lyrics draw attention to some historical dramatic irony in the narrative. ${ }^{7}$ However, the show's opponents would consider this use to be less critical than Anderson supposes. ${ }^{8}$ For Daniel Mendelssohn, just as an audience is expected

\footnotetext{
${ }^{6}$ Mark Greif, 'You'll Love the Way It Makes You Feel', London Review of Books, 30(20), 23 October 2008, 15-16

7 Tim Anderson, 'Uneasy Listening: Music, Sound, and Criticizing Camelot in Mad Men', in Gary Edgerton (ed.), Mad Men: Dream Come True TV (London, 2011), 72-85.

8 There are numerous examples of advertisers clearly failing to spot the irony in their use of a song:see Bethany Klein, 'Taming Rebellion', in her As Heard on TV: Popular Music in Advertising (Farnham, 2009), 97-120. There are many others where the irony is deliberate and works to good effect-for example, the use of an upbeat, polished cover of Janis Joplin's anti-consumerist 'Mercedes Benz' (1970) for-what else?—a Mercedes Benz commercial (1997).
} 
to 'get' an advert, scenes contain none of the tension or jeopardy necessary for genuine drama, one simply has to put the pieces of the jigsaw puzzle together in order to 'get' what is going on.' The audience, he says, is just 'supposed to get' the presence of account executive Lane's black playboy bunny girlfriend, for example, 'the way we're supposed to "get" an advertisement in a magazine'. While there is certainly ironic counterpoint between song and narrative in Anderson's examples, Mendelssohn would argue that each case is more about the satisfaction of riddle-solving than imparting anything of critical value.

'Getting' in advertising is the necessary corollary of the shift to affect. Once, the job of the advert was to explain in painstaking detail why the product was so effective. Explanation, however, diminishes mood, sentiment, sensuality. Instead, texts now offer clues that ease viewers into the affective world of the advert rather than giving them any concrete information about the product. Even though the linguistic, signifying content might be sophisticated, the basic message of the advert is often so primitive it would sound ridiculous if expressed in words-this product will make you more attractive, more confident, or ensure the safety and comfort of your family. Greif and Mendelssohn are right that many sections of Mad Men are better understood as affective adverts than scenes conforming to the norms and expectations of (contemporary complex) narrative TV. ${ }^{10}$ But the purpose of this essay is to show through three examples that there are at least some 'musical moments' where the viewer is unable simply to solve the apparent linguistic or narrative puzzle presented to them and thereby earn an enjoyable sensuous experience: Mozart's aria 'Voi che sapete' in 'Marriage of Figaro' (series 1, episode 3; original air date in the US: 7 August 2007), George Jones's country hymnal, 'Cup of Loneliness', in 'The Mountain King' (S2, E12; 19 October 2008), and the Beatles' experimental 'Tomorrow Never Knows' in 'Lady Lazarus' (S5, E8; 6 May 2012).$^{11}$ In these cases the puzzle remains unsolvable and the sensuous experience cannot be resolved into familiar concepts. The viewer is thereby forced to engage in critical thought about the events they experience.

\section{Mad Men}

Greif's review of the first series of Mad Men has provided the main ammunition for much of the

\footnotetext{
${ }^{9}$ Mad Men 'advertises' rather than 'dramatizes' its themes: Daniel Mendelsohn, 'The Mad Men Account', New York Review of Books (24 February 2011).

${ }^{10} \mathrm{I}$ take my general view of how narrative works in audiovisual media from David Bordwell, Narration in the Fictional Film (Madison, 1985). The more specific mechanics of contemporary 'complex television' are covered by Jason Mittell, Complex TV: The Poetics of Contemporary Television Storytelling (New York, 2015). Both books explicitly exclude affect from their discussion, something Bordwell labels 'excess'.

${ }^{11}$ I borrow the term 'musical moment' from Ian Conrich and Estella Tincknell (eds), Film's Musical Moments (Edinburgh, 2006).
} 
subsequent media and scholarly criticism. ${ }^{12}$ His main grievance is that it exemplifies 'Now We Know Better' TV. He argues that the show's chief source of pleasure is the smug satisfaction of observing outmoded attitudes such as 'male chauvinism, homophobia, antisemitism, workplace harassment, housewives' depression, nutrition and smoking'. This would not be so bad were it not coupled with the 'Now Doesn't That Look Good' TV already mentioned, which doesn't just apply to the eroticized consumer products of the 1960s, but extends to nostalgia for the very prejudices that have supposedly been left behind. ${ }^{13}$ The series, then, was cynically designed to appeal equally not only to the identitarian left who delight in their moral superiority but also to conservatives who look back fondly to a time when women, people of colour, and homosexuals all knew their place.

These criticisms have been fiercely contested by the show's adherents. Andrew Carew counters that Mad Men 'doesn't ring true as a case of "Now We Know Better" because the more things have changed, the more they've stayed the same'. ${ }^{14}$ For those who draw inspiration from the 1960s and now mistake policing the linguistic expression of racism, sexism, and homophobia on social media for political activism, the show deflates the fantasy that the counterculture ever posed a real threat to the established order. It underlines, for example, just how badly nascent third-wave feminism failed. As Kathy Knapp puts it: '[the] show does not chronicle the last gasp of the white male [...] but outlines the way that a wily old guard has followed the advice of E. Digby Baltzell [...] by "absorbing talented and distinguished members of minority groups into its privileged ranks" in order to maintain its grip on power'. ${ }^{15}$ The series may allow the viewer to luxuriate in 1960s fashions, but as Lauren Goodlad observes, 'Mad Men's objective situation is not the 1960s at all but today's neoliberal condition: a Weltrustand in which the radical 1960s are not so much "waning" as derided and repressed, if never quite demythologized or forgotten'. ${ }^{16}$ Anyone who thinks the show is about identity politics, then, is bound to view it as superficial. As I will draw out in my three analyses, Mad Men demonstrates how consumer culture is enervating for everyone, even its supposed beneficiaries. It also reveals how, behind the pleasure-seeking sex, drugs, and rock 'n' roll, the 1960s counterculture

\footnotetext{
12 Greif, 'You'll Love the Way It Makes You Feel'.

13 This is the substance of the feminist critique of the series. See Katixa Agirre's two articles for example: "Whenever a man takes you to lunch around here": Tracing post-feminist sensibility in Mad Men', Catalan Journal of Communication \& Cultural Studies, 4 (2012), 155-70; “Am I supposed to say how shocked I was?”: Audience responses to Mad Men', European Journal of Cultural Studies, 17 (2014), 631-46.

14 Anthony Carew, 'Mad Men: Plus Ça Change ...', Metro Magaz̧ine 169 (2011), 126-29.

${ }^{15}$ Kathy Knapp, 'Return of the King: Mad Men and the Greatest Story Ever Sold', LA Review of Books, 2 April 2015.

${ }^{16}$ Lauren M. E. Goodlad, 'The Mad Men in the Attic: Seriality and Identity in the Narrative of Capitalist Globalization', Modern Language Quarterly, 73 (2012), 201-35.
} 
contained an emancipatory kernel that was and remains a genuine antidote to me-oriented consumerism.

From this viewpoint, the 'Now Doesn't That Look [and Sound] Good' becomes crucial to the critical animus of the show. In the collective memory, the 1950s were the time when the ideology of the American Dream came closest to reality-before the country gave an unfair legup to blacks and women, and unpatriotically moved all its blue-collar jobs abroad. ${ }^{17}$ By the time the show begins in 1960, Don, who grew up dirt poor in a bordello, has traded on his looks, charm, and wit (skimping a little on the supposedly necessary hard work) to reinvent himself as a successful advertising executive. Don is not just living the dream, but the rose-tinted fantasy version as seen on TV. Nevertheless, he is still deeply and chronically unhappy. The majority of reviewers, bloggers, and viewers who post comments believe Don possesses certain character flaws and is responsible for his own misery; they maintain that his salvation lies in further selfreflection and reinvention, and like to debate how he should go about this. ${ }^{18}$ What I am claiming, by contrast, is that Mad Men counts as 'art' in a specific Deleuzean sense: 'artists are clinicians, not with respect to their own case, nor even with respect to a case in general; rather, they are clinicians of civilization. ${ }^{, 19}$ Don's symptoms are our symptoms. While they might be instantiated at the level of the individual, Don's blind spots, niggling anxieties, and full-blown depressions are the result of living in the very consumerist society his team's creative efforts do so much to produce. My main claim, then, is that the three musical moments under discussion exemplify the sonic aspect of a more general symptomatology of consumer capitalism that the show performs.

\section{Symptomatology}

While Deleuze's aesthetics is meant to address many of the weaknesses of Marxist ideology critique, any attempt to develop it to investigate mainstream TV is confronted with the same problem Marxist television and cinema critics have always faced; namely, that neither seems capable of mounting any meaningful resistance to the powerful appeals of affective advertising. ${ }^{20}$ As Claudia Gorbman, following Hans Eisler and Theodor Adorno, explains: by

\footnotetext{
${ }^{17}$ See, for example, Arlie Hochschild, Strangers in Their Own Land: Anger and Mourning on the American Right (New York, 2016).

${ }^{18}$ I cite specific instances later in the essay.

${ }^{19}$ Gilles Deleuze, The Logic of Sense [1969], trans. Constantin Boundas, Mark Lester and Charles Stivale, (New York, 1990), 237.

20 This, of course, includes the television shows themselves, which, if not placing products, they are at least preparing viewers to accept what the adverts are going to sell them. Unsurprisingly, US television is exemplary here: think of the constant drinking and eating on shows like Friends (1994-2004), How I Met Your Mother (2005-14), or Big
} 
submerging the viewer in a warm bath of affect, music operates in narrative cinema to promote the most fundamental aspects of capitalist ideology. It sutures the viewer into the diegesis, making its highly strange mode of perception seem natural. By remaining subservient to the narrative, it generates a unified film world and the corresponding illusion of an individual (creative) identity. And by making the viewer less likely to question the (ideological) content, it produces an 'untroublesome social subject'. ${ }^{21}$ Marxist critics, observes Kathryn Kalinak, have then been divided on the question of whether music, or music-image, can ever rupture the apparently unmediated experience of cinema and television in such a way that unmasks the "the intellectually and emotionally alienating effects of life under advanced capitalism'.22

One alternative, championed by Brian Ott amongst others, is to fight fire with fire-to provoke political resistance by aping the techniques of affective advertising. He believes that $V$ for Vendetta (2006) succeeds as political cinema not by revealing the true material conditions, but by remoulding viewers at a 'visceral' level. He refers to affect's nature as a bundle of intensities that motivates us, encourages us to adopt some attitudes and not others; these motivations and attitudes in turn can be thought of as incipient action. Audiovision's critical potential is then realized in its ability to '[move] viewers at a material bodily level to enact a politics of resistance and revolt. ${ }^{23}$ We don't need to look very far to see how terrifyingly effective electronic media of all kinds are at affectively motivating audiences into political action. But, unfortunately, it's far better at stoking the reactionary politics of fear, hatred, and tribalism than encouraging people to embrace a healthier, less self-destructive way of life.

Deleuze's aesthetics also values the non-narrative, alinguistic, or asignifying pole of expression, but the aim is not to expose incorrect thoughts (ideology) or to circumvent thought per se (advertising, propaganda, Ott's visceral political cinema), but to break away from the overarching manner of thinking that splits the world into individual (objective and subjective) identities and supposes a correspondence between mental representations and the world. ${ }^{24}$ Art

Bang Theory (2007-19), which normalizes excessive consumption.

${ }^{21}$ Claudia Gorbman, Unheard Melodies: Narrative Film Music (Bloomington, 1987), 57.

22 Kathryn Kalinak, Settling the Score: Music and the Classical Holywood Film (Madison, 1992), 32.

${ }^{23}$ Brian L. Ott, 'The Visceral Politics of V for Vendetta: On Political Affect in Cinema', Critical Studies in Media Communication, 27 (2010), 39-54, at 50.

${ }^{24}$ Although I don't address it directly in this particular article, my Deleuzean approach to television music is strongly influenced by the work of Amy Herzog, Anahid Kassabian and Steven Shaviro, particularly their respective titles Dreams of Difference, Songs of the Same: The Musical Moment in Film (Minneapolis, 2010); Ubiquitous Listening: Affect, Attention, and Distributed Subjectivity (Berkeley, 2013); and Post Cinematic Affect. (Ropley, 2010). Published too late to have any influence here, Phil Powrie's Music in French Cinema: The Crystal Song (London, 2017) will surely also be important as I develop these ideas further in the future. 
produces 'pure sensations' (impersonal affects and percepts) which enable the viewer to escape the 'common sense' that characterizes this 'dogmatic image of thought'. ${ }^{25}$ But while it may short-circuit the spectator's cognitive processes and 'act immediately upon the nervous system' during the aesthetic experience itself, the ultimate aim is to provoke the viewer into perceiving the world as a sea of force fields operating at multiple levels, directing flows of energy, matter, thought. Bodies are not primary, but are precariously maintained by these flows in a state of dynamic becoming, from which the new is always liable to emerge. ${ }^{26}$ Symptomatology focuses on achieving the 'good' or 'healthy' life, which involves the individual or the collective embracing the forces it encounters, using them to transform itself, increasing its 'power to live', and 'opening up new possibilities of life'. ${ }^{27}$ A symptomatological analysis, then, will diagnose symptoms of a 'bad' or 'unhealthy' life, which reacts against potentially transformative forces, leading to degeneration and exhaustion. The symptoms may be expressed affectively within the artwork, but the result is to invite the viewer to think about what specifically makes the mode of life shown unhealthy, and how they, as part of the collective, might go about diminishing the reactive and augmenting the active forces.

Each musical moment considered here is placed at a crucial juncture in the narrative and its importance highlighted, leading the viewer to believe that it might serve as a key to the episode, tying the intricate inter- and intra-textual threads spun in the episode together in the manner of an especially complex affective advert. However, the opposite happens: the songs turn the episodes into intractable problems, leaving audiences—as evidenced by internet discussions - unable to reach a consensus about what it all means. The wider milieu is carefully established throughout each episode by reference to multiple extra-televisual media-including literature, the original domain of symptomatological analysis. In each song, the words are given a particular musical expression that reverberates with the affects found across the wider context of the episode (or even the season or series as a whole). But the musical affect never simply articulates for the viewer what Don is personally feeling. Instead, we hear the tensions between the psychological and social forces acting upon Don's body and his (body's) reaction to them. The music allows the viewer to hear how Don is distorted, warped, contorted by the forces that

${ }^{25}$ Gilles Deleuze and Félix Guattari, What is Philosophy? [1991], trans. Hugh Tomlinson and Graham Burchell (New York, 1994), 163ff.

${ }^{26}$ Deleuze, Francis Bacon, The Logic of Sensation [1981] (London, 2003), 34. Deleuze actually says 'bypass the brain', but he is drawing on Bacon's description of his own work here. In reality there is no brain-body dichotomy: the brain is part of the nervous system and body, and is very much involved in 'pure sensation'; it is actually the cognitive resolution of sensory experience into objects with certain fixed or known properties that is bypassed in the aesthetic experience.

${ }^{27}$ Daniel Smith, “'A Life of Pure Immanence”: Deleuze's “Critique et Clinique” Project', in Essays on Deleuze (Edinburgh, 2012), 192. 
appropriate him, exploit him, and express themselves through him. ${ }^{28}$ It turns Don into a sign, a problem, or a symptom. The result is to send the viewer into interpretative overdrive, seeking both to explain the causes of the symptoms and to discover therapies that might mitigate them.

\section{'Marriage of Figaro'}

How might one resist the 'joys of marketing, ${ }^{29}$ especially when they are bound up with the exquisite pleasure of love, which, we are incessantly reminded, is crucial to our life project and overall sense of wellbeing? Marketing that involves love is all the more difficult to resist when its narratives and associated structures of feeling repeat so frequently and so vividly in novels, operas, films, and commercials that they are accepted as universal. As an ad man, Don appreciates that it's his job to maintain the fantasy of 'enchanted love' as an ideal people can approach through consumption. As he remarks to a stranger in a bar: 'The reason you haven't felt it is because it doesn't exist. What you call love was invented by guys like me to sell nylons. ${ }^{30}$ One might continue his line: 'to gullible fools like you'. Don, then, seems to have found a way to resist the joys of marketing-irony. He is the detached, rational observer who understands what's really going on. 'Marriage of Figaro' poignantly illustrates, however, that rather than a successful strategy for resistance, irony is an inevitable consequence of living the painful contradictions that characterize contemporary forms of love. While Don's pain reaches its apogee in the musical moment under discussion here, it only fully counts as a sonic symptomatology because it gathers together Don's (non-musical) experiences from across the episode.

'Marriage of Figaro', set in 1960, is separated into a business half at the Sterling-Cooper office, and a domestic half at Don's house, where his family are hosting his daughter Sally's seventh birthday party. At work Don begins an affair with a client, Rachel Menken, a strongminded Jewish department store owner. He avoids connecting emotionally with her when she opens up to him; although she reveals countless intimate details about herself, Don deflects questions about his personal life. This is partially because he's married, and partially because he's hiding his 'true identity'—Dick Whitman, orphaned son of a prostitute—so can't be honest with anyone. ${ }^{31}$ But a third reason only becomes apparent when the musical moment folds

\footnotetext{
${ }^{28}$ Gilles Deleuze, Nietzsche and Philosophy, [1962] trans. Hugh Tomlinson (Minneapolis, 1983), 3.

${ }^{29}$ Gilles Deleuze, 'Postscript on the Societies of Control', October, 59 (1992), 3-7 at 7.

30 'Smoke Gets in Your Eyes' (S1, E1; 19 July 2007).

31 Don's condition, which Goodlad calls 'virtual Jewishness', is a structural feature of late capitalism in which 'the minority subject's aberrant particularity and the majority subject's universalist status collide.' Goodlad, 'Mad Men in the Attic', 215. Confirming this, a recent poll showed that $56 \%$ of men and $66 \%$ of women experience 'imposter syndrome' in the office: Rachel Sharp, 'Two-thirds of Women Experience Imposter Syndrome', HR
} 
together the disparate facets of the episode. Don has spent too much time constructing fantasies in which love is central to the individual's emotional self-fulfilment. He is responsible for circulating the means for talking about and expressing this fantastical version of love. He knows, then, that as the product of the imagination, love is opposed to reality. ${ }^{32}$ The problem is that, as David Halperin observes, irony is 'incompatible' with 'intense, overwhelming sensation' such as the experience of 'sexual passion'; Don's detached stance has hobbled his capacity to take pleasure in his own ardour. ${ }^{33}$

At home, the cracks in his marriage-which, until now, has been portrayed as the 1950s ideal Don's adverts sell—are finally revealed. Don would like to spend his day off lazing around drinking beer and smoking. His wife Betty has better ideas, ordering him to do various chores: make the P-L-A-Y-H-O-U-S-E (Sally's surprise birthday present), take a film of the party, go and pick up the cake. Adverts like Don's have promised himself and his wife an emotionally adventurous and fulfilling domestic life. The modern home, however, is characterized by the marked rationalization of both time—-sleep, meal, and leisure activities are highly routinizedand space — think of the rows of identical dream houses, the optimized mall layout. Such relentless predictability is hardly conducive to the emotional excitement consumers are led to expect and to believe others are achieving easily. Betty's deep and abiding disappointment is revealed slowly throughout the season, but Don confesses his own dissatisfaction in this episode to Helen - a divorced single mother treated as a threat to suburban order by the moms at the party, and as offering a welcome frisson of sexual tension by the pops. In the garden they elliptically begin to confide to each other their desire to escape the suburban conformity, with its suffocating codes enforced by networks of gossiping women-until those very women ensure Betty runs out to nip any potential threat in the bud.

As the festivities begin, Don tunes the radio to a live performance of The Marriage of Figaro (1786), snippets of which can be heard throughout the party. ${ }^{34}$ The longest of these is Cherubino’s aria 'Voi che sapete', which plays while Don makes the film Betty has requested.

Magazine (31 July 2018).

32 At the end of this section, I will borrow from Eva Illouz, who bases her discussion of how media shapes modern attitudes to love on Adorno's insight that 'Romantic love and fantasy have become the object of cultural suspicion because "fantasy is only tolerated when it is reified and set in abstract opposition to reality." Why Love Hurts: A Sociological Explanation (Cambridge, 2012), 199.

33 David Halperin, 'Love's Irony: Six Remarks on Platonic Eros', in Shadi Bartsch and Thomas Bartscherer (eds), Erotikon: Essays on Eros, Ancient and Modern (Chicago, 2005), 48-58 at 49.

34 We know that Elvis had just returned from Germany, so this is likely to have been 5 March 1960. However, the only Saturday afternoon matinee of The Marriage of Figaro (which the Met have always referred to as Le Nozze di Figaro) in 1960, took place on 23 January. Moreover, Cesare Siepi and Elisabeth Söderström took the lead roles, not Robert Merrill and Joan Sutherland as announced in the episode, who never sang Figaro and Susanna at the Met. 
When the viewer sees ordinary shots of the party (i.e. through the television camera lens), they hear the ambient noises of the party; when they see the footage taken on Don's Super- 8 , which has no microphone, the silence is replaced by the music from the radio alone. The aria thus shifts between diegetic and non-diegetic function depending on the type of camera being used. In keeping with the words, in which the adolescent Cherubino begs Susanna and the Countess Almaviva to explain the secret of love, Don observes three contrasting types of love through his camera. First is the familial love he feels for his daughter, who he catches playing a party game with the other children. Second is predatory sexual lust. One of the fathers approaches Helen and offers to 'help' her by playing ball with her son or taking him to the beach. Don captures her dignified but pointed rebuff. Finally he spies a married couple who, believing they are alone, take the opportunity to exchange a moment of genuine affection. When the music began, it shifted between background noise and an aural patina matching the graininess of the cine film. It grated against, or was at least irrelevant to, Helen's put-down of the creep. But in this final part of the scene, the music at the party increases in volume and takes on the role of a composed score. The music combines with Don's anguished facial expression to produce a freefloating, timeless, placeless feeling of longing. In their yearning, Don and Cherubino mutually become one another across the centuries. ${ }^{35}$ In other words the result is what Deleuze calls an affection-image, a moment of 'pure becoming', except it is achieved audiovisually, rather than just visually, as in his examples. ${ }^{36}$

Plate 1. Don's expression as he witnesses a moment of genuine affection. 'Marriage of Figaro', season 1, episode 3: 36m, 49s.

What part does the music play in this audiovisual affection-image? Firstly, of course, Mozart has already mobilized a series of musical devices to generate the powerful bodily manifestation of Sebnsucht. The first few minutes of the song-heard during the first two vignettes of love-cleverly combine melancholy with elation (by superimposing a contemplative melody over a bouncing accompaniment) and veer giddily between joy and sorrow (by starting or ending consecutive lines with major and minor versions of the same chord) to generate Cherubino's particular version of how it feels to be a teenage boy surrounded by attractive yet unattainable women. ${ }^{37}$ It is no coincidence, however, that the music has reached the agitated $\mathrm{G}$ minor section when Don witnesses the tender kiss between the married couple.

\footnotetext{
35 Smith, 'Deleuze’s “Critique et Clinique” Project', 204.

${ }^{36}$ Deleuze, Cinema I: The Movement Image [1983], trans. Hugh Tomlinson and Barbara Habberjam (London, 2013), 97-137.

${ }^{37}$ A particular case of (teenage) love elucidates what Deleuze calls, following Bergson (although the source is actually Hegel), the 'concrete universal' by participating in it. 'Bergson's Conception of Difference' [1956], in Desert Islands and Other Texts, trans. Michael Taormina (New York, 2004), 32-51, at 43.
} 
I am pursuing some sunny ray,

But it eludes me, try as I may.

I can't stop sighing, hard as I try,

And then I tremble, not knowing why.

From this dilemma I find no peace,

And yet I want it never to cease. ${ }^{38}$

Whereas the ritornello presents the usual emotional ups and downs of being in love, the middle section produces the somatic markers of love that Cherubino expresses verbally. 'I can't stop sighing, hard as I try': his breathless speech patterns are followed by a little sighing figure at the end of each line. The sighs are not only dissonant with the prevailing chord, but the chord itself is also a long-held dissonance. On the first two occasions, the bass note comes in a semiquaver late: a disconcerting jolt after the on-the-beat pattern mostly adhered to thus far-the unanticipated 'trembling'. Further, the resolution is only momentary, suddenly being interrupted by a fortissimo, offbeat, chromatic appoggiatura. It is at this exact point in Cherubino's hurried delivery that he finally has time for a quick intake of breath. The combined result is that we hear Cherubino's body convulse. This auditory expression of impersonal affect-i.e. the intensities that act upon him, that cause him to lose control of his body-is further augmented by the unstable harmony throughout this passage. After the perfect cadence in $G$ minor on 'non so cos'è', there is a passage of free-floating, dynamic harmony leading back to the B-flat major of the ritornello. The major-minor alternations from the ritornello are also telescoped here (c minor to c seventh; d minor to d seventh). Cherubino's involuntary spasms, therefore, occur in a body that is already untethered and tense. ${ }^{40}$

The meaning of Cherubino's words and his specific circumstances are likely to be lost on most viewers on their first viewing. Nevertheless, the sensation that Mozart has captured in this music is available for reactivation by a listener at any time, which is what happens in the new audiovisual context. Apart from the musical anachronism, a number of other factors are responsible for divorcing the affect from its specific context—as Deleuze requires for the

\footnotetext{
38 Translation by Ruth and Thomas Martin in Wolfgang Amadeus Mozart, The Marriage of Figaro (New York, 1947), 142-43.

39 As Antonio Damasio vividly explains feelings (including emotions) begin with bodily (physiological) experiences before the mind begins to associate (acculturated) ideas with them: Looking for Spinoza: Joy, Sorrow and the Feeling Brain (London, 2003), 83-88.

40 One may justifiably argue that Mozart was working with a system of legible semiotic codes and that many of the features here are so common in music of this period as to form something akin to a language. But it should be remembered that most musical semioticians agree that musical signs are always Peircean iconic signs, that is they always contain something of what they represent. See for example, Naomi Cumming, The Sonic Self: Musical Subjectivity and Signification. (Bloomington:, 2001).
} 
affection-image. The technological mediation of both music and image alters the way in which the musical sensation is actualized. Don starts out by watching the couple through his Super-8, the grainy, colour-saturated image already imbued with the nostalgia the advertising industry sells as signifying perfect family memories. As evidenced by his pitch for the Kodak Carousel later in the season, the camera can lie, fabricating a simulacrum of the dream life while the reality is anything but. ${ }^{41}$ Now that Don is filming something genuine, instead of bathing the image in the halo of nostalgia, the Super- 8 places it irretrievably far from him. The metaphor of distance is then repeated in the auditory mode: the music is heard to come from the radio in another room, metaphorically placing the love that is the source of his physical pain in this moment out of his reach. The technological products used to construct narratives about happy family lives and lend an aura of cultural sophistication to a house party, serendipitously align to produce longing for love as pure affect.

Plate 2. Don ponders the Volkswagen Beetle ad in Life magazine. 'Marriage of Figaro', season 1, episode 3: 0 minutes, 39 seconds.

It is not possible to fully understand how this moment of pure affect functions as a sonic symptomatology until we have explored what happened in the first half of the episode. Helen supplies the link between the two halves. Just as the women latch on to her long walks as a sign of her oddness, the men notice that she drives a Volkswagen Beetle. At the start of the episode, Don, on his usual commute into the city, is flicking through Life magazine and happens on an advert for the Beetle (Pl. 2). ${ }^{42}$ The 'Think Small' campaign, which lasted throughout the $60 \mathrm{~s}$, is considered by advertisers to be one of the most radical, influential, and successful of the twentieth century. ${ }^{43}$ One innovation is obvious. Whereas typical car ads of the era were boastful, emphasising the size and the speed of the car, the Beetle ads draw attention to the car's weak points. ${ }^{44}$ The tagline 'Lemon', for example, is slang for 'ineffective' and also makes fun of the car's peculiar shape. Less obvious, but more wide-ranging in its influence, is the relationship of

\footnotetext{
${ }^{41}$ Don loads up the carousel with photos depicts his own family's 'Kodak moments', even though his work and extra-curricular activities ensure he his absent from most of them. Don's pitch:

Nostalgia means 'the pain from an old wound'. It's a twinge in your heart far more powerful than memory alone. This device isn't a spaceship, it's a time machine. It goes backwards, forward. It takes us to a place where we ache to go again 'The Wheel' (S1, E13; 18 October 2007).

42 The campaign was run by real Madison Avenue advertising agency Doyle, Dane, Berbach (DDB). Although Don and his colleagues react as if it were completely new in 1960, the campaign actually began in 1959 with the 'Think Small' ad. DDB still have the VW account.

43 Advertising Age, for example, ranked it the top campaign of the twentieth century.

${ }^{44}$ Compare the VW ad with these more typical 1960 ads: http://www.oldcaradvertising.com/Pontiac\%20\&\%20Oakland/1960/1960\%20Pontiac\%20Ad-09.jpg http://oldcaradvertising.com/Ford/1960/1960\%20Ford\%20Ad-04.jpg
} 
the image to the text:

In the post-war period, and especially since the early 1960s, the function of text moved away from explaining the visual and towards a more cryptic form, in which text appeared as a kind of 'key' to the visual.

In all, the effect was to make the commercial message more ambiguous; a 'reading' of it depended on relating elements in the ad's internal structure to each other, as well as drawing in references from the external world. ${ }^{45}$

In contemporaneous car ads, the text was information-based and direct, explaining the technical details of the car in a way that simply reinforced the message of the images. The tagline 'Lemon', by contrast, poses the consumer with a conundrum to which the only solution is to read the text. This form of advertising isn't actually that radical: the advert still functions to impose a set of pre-existing meanings on the consumer's actions (i.e. purchasing decisions). However, what made the Beetle advert possible was the realization that the (linguistic) 'meaning' of adverts is actually irrelevant to what they 'do'. If people don't understand an advert, it might not matter if the atmosphere attracts them in some way-it might even help to increase the allure. On the other hand, if the consumer invests the effort into deciphering the advert, which they are already more likely to do if they are attracted to the mood, they will spend more time in the affective world of the advert and are thus more likely to form an emotional attachment to the (fantasy version of the) product. They are also subsequently more likely to discuss the advert with other people. Of course the Beetle's use-value is important to Helen: it's an affordable vehicle that gets her from A to B. But we suppose that any 'joy' the Beetle gives her is due to the marketing which associates her with the campaign's self-deprecating humour, humility, and eccentricity. ${ }^{46}$ The downside is that Helen's infinite creativity (her essence) — as demonstrated in her resilience in the face of abuse from both men and women at the party—is reduced to a fixed and measurable identity.

While Don and his creative team are initially baffled, over the course of the series they internalize and start producing precisely this type of advert. Episodes of Mad Men often function in a similar way: they set viewers cryptic challenges that they are then invited to make sense of by relating various parts of the episode together, and by drawing on often quite oblique or

\footnotetext{
45 William Leiss, Stephen Kline, Sut Jhally, Social Communication in Advertising: Persons, Products and Images of WellBeing (New York, 1990), 199.

${ }^{46}$ Not just the campaign, but the company itself. When watching an advert it is implicit that the advert is articulating the personality of the company_-'marketing has become the centre or "soul" of the corporation. We are taught that corporations have a soul, which is the most terrifying news in the world.': Deleuze, 'Postscript on the Society of Control', 6 .
} 
obscure references to real world events, as well as to literary, cinematic, and, of most relevance here, musical artworks. This being the third episode of the series, it could even be argued that, just as the Beetle advert is training Don's team to understand this kind of advert, this episode is training the show's viewers how to watch Mad Men. By titling the episode 'Marriage of Figaro', Weiner's creative team are signalling to the audience that the music playing during Sally's birthday party has some particular significance. Most reviewers acknowledged that they needed to do some research in order to work out how the opera related to the episode. Just as the 'Lemon' tagline forces the consumer to read the text in order to decipher the Beetle advertisement, the title 'Marriage of Figaro' forces Mad Men viewers onto Wikipedia to decipher the show. ${ }^{47}$

Betty parallels the Countess, who is deeply unhappy because she loves the Count, but he is always off chasing younger women. The Count, like Don, doesn't want to hurt his wife, but feels he is driven by a force he can't control. The wives are prepared to forgive their husbands, however painful it might be, as long as each man keeps returning to his wife. ${ }^{48}$ Further, Cherubino is a trouser role- a young woman playing a teenage boy, who, during the course of the opera, ends up dressing as a woman. This fluidity of identity is a further allusion to Don's big secret, which even Betty isn't aware of yet. The show, then, operates just like the Beetle advert, and with the same payoff. The episode generates a bundle of sensuously enjoyable nostalgic affects and cryptic puzzles to lure viewers into its world; but in the digital age the puzzles serve the further function of encouraging its 'prosumers' into extra online engagement, keeping the show in circulation, and the puzzles' high-brow subject matter increasing the show's standing. ${ }^{49}$

Like the best popular culture, the creative team treat this commercial strategy as an opportunity for creativity. Alongside the advert-level puzzle, the musical moment under discussion sets a genuine problem. Given that Don is responsible for the cultural technologies that stimulate and discipline the bourgeois imagination and experiences first-hand the ennui

${ }^{47}$ This is the film music function Anahid Kassabian calls 'allusion': Hearing Film: Tracking Identifications in Contemporary Hollywood Film Music (New York and London, 2001), 50. However, it is a peculiarly modern form: whereas in Kassabian's definition, the allusion 'can evoke another whole narrative for the perceiver familiar with the excerpt,' the modern television screen is effectively hyperlinked, meaning that every viewer can become familiar with the narrative allusion immediately.

48 This gives the viewer some important information: at this point it is still uncertain whether Betty knows about Don's affairs; this external commentary seems to confirm that she does.

49 This was part of AMC's crafty strategy to charge higher subscriptions on the back of a few prestige lossleading shows. Anthony Smith, 'Putting the Premium into Basic: Slow-Burn Narratives and the Loss-Leader Function of AMC’s Original Drama Series', Television \& New Media, 14150-166. 
produced by the suburban domestic experience he is selling, his ironic attitude to love, his willingness to tolerate his family life (liberally supplemented by whisky and women), and his attitude to the women he is 'in love with' are all plausible. But how does his ironic detachment square with the musical moment in which he becomes Cherubino (and vice versa), longing for 'enchanted love' like a sentimental teenager? The scene gathers all the aspects of his attitude to love from across the episode into a 'table of symptoms' that now constitutes a problem. Instead of bundling together a set of alluring affects that the viewer may wish to partake in, it hints at a configuration of reactive-i.e. life-sapping — forces that result from the manner love is exploited in consumer culture and that are actualized in situations as different as Don's and Cherubino's. Since viewers are themselves overpowered by the same media technologies and their suite of emotional fictions, their first instinct is likely to assume that Don-like everyone else-simply craves true love: if only he could just meet the right person, be true to himself, ... . ${ }^{50}$ But the style of music and image-i.e. the qualities that transform it into an affection-image-estrange the viewer from an emotional response that would otherwise have seemed normal or necessary, transforming it into something surprising and contingent, something worthy of investigation, something that may be learned from. ${ }^{51}$ In other words, one is encouraged to interpret the symptom, which, for Deleuze, means uncovering 'the force [or "configuration of reactive forces"] which appropriates the thing, which exploits it, which takes possession of it or is expressed in it. ${ }^{52}$

To demonstrate how a viewer may set about interpreting the configuration of reactive forces appropriating, exploiting, and taking possession of Don in the musical moment, I turn to Eva Illouz, an empirically (rather than artistically) minded clinician of bourgeois love. First, while ironic detachment might inoculate Don from disappointment in any particular encounter, it entails a more enduring discontent. For, however much he knows that enchanted love is just a fantasy designed to sell holidays in the sun and however much he is able to renounce it in everyday life, he can't help the fantasy from structuring his desire. Even the hard-boiled ad exec longs for true love. Second, while Don can neither escape the fantasy nor the intense emotions bound up with it, he still finds a 'means of movement, a way of transforming the situation', the

\footnotetext{
50 This was certainly my response, and the response of every reviewer/blogger I read.

51 Jonathan Flatley, Affective Mapping: Melancholia and the Politics of Modernism (Cambridge, MA, 2008), 6-7. Flatley doesn't spell it out, but his 'affective mapping' seems to me to be a combination between Deleuze's 'pure affect' (as exemplified by the affection-image) and symptomatology, except that he takes a reader- (or viewer-) centred, and hence self-reflective approach, rather than Deleuze's (with Guattari in Kafka) focus on the author.

52 Deleuze, Nietzsche and Philosophy, 3. Deleuze continues: 'A phenomenon is not an appearance or even an apparition but a sign, a symptom which finds its meaning in an existing force.'
} 
critical element necessary in a symptomatology. ${ }^{53}$ While the full pleasure of love is closed off to Don in reality, he is still free to enjoy the fantasy - even if his version is akin to the painful enjoyment offered by grief. ${ }^{54}$ Since Don's creative transformation of the situation takes place at a distance, there is no messy reality to interfere with the perfect fantasy; he exerts complete control over the fiction and can thus regulate its aesthetic form. He also manages to elude the logic of consumption: he does not intend or even believe it is possible to find 'true love'. His desire is not attached to an object, but melds seamlessly with fantasy. Ultimately, however, Don's attempt to find a movement away from his predicament fails. Relying on a self-generated fantasy that conforms to a predetermined affective repertoire in order to avoid consummation/consumption can never lead to genuine creative transformation- that would require the unexpected consequences of an open encounter with another. It turns out, then, that not even Don Draper can resist the joys of marketing.

\section{'Mountain King'}

After episodes such as 'Marriage of Figaro', the title 'Mountain King' directs viewers to Ibsen's Peer Gynt (1867) to search for parallels and elucidation. Don's sojourn in California, which began in the previous episode, 'The Jet Set', seems to correspond to the play's dream sequence, an intuition supported by the trip's hallucinatory quality and bizarre coincidences. In 'The Jet Set', Joy—a 'woman in a green dress' like the Troll King's daughter in the play—tempts him to join her in a life of hedonistic excess with her group of idle rich travellers. In 'Mountain King', he travels to see Anna Draper, the widow of the real Don Draper. She is the only person who knows his true identity and, free to be the original Dick Whitman around her, he is the most relaxed and happy we ever see him. Many bloggers and commenters believe that Anna is Solveig to Don's Peer, able to offer him absolution. But while she might perform this role, the episode title suggests that Anna's house is 'The Hall of the Mountain King' —an impression reinforced by one of her piano students playing Grieg's piece of that name (1876) when Don arrives_and therefore the site of reckoning rather than forgiveness.

Peer Gynt is about identity, self-formation, and autonomy, themes confronted head-on when Peer meets the Troll King. In the philosophical fulcrum of the play, the King asks Peer: 'What is the difference between man and troll?' The King's cryptic response to his own question is: to live like a man is to live by the maxim 'to thine own self be true', to live like a troll, 'to

\footnotetext{
${ }^{53}$ Ronald Bogue, Deleure on Literature (London, 2003), 110.

54 Illouz illustrates the phenomenon of 'autotelic desire' with a number of (real-world) examples in which people seek to delay consummation of a romantic relationship with another in order to maintain the fantasy and avoid disappointment. Why Love Hurts, 232-36.
} 
thine own self be enough'. The life of sensual pleasure offered by Joy, without any family or other ties, resembles a troll-like existence. But does being true to oneself-living as a man according to the Troll King-represent the best alternative? Most reviewers and bloggers think so: if only Don could be more honest to himself and others, commit to a single woman, find his true vocation, he would find peace, love, and happiness. ${ }^{55}$ In the quasi-religious baptismal scene that ends this episode, which sees Don saunter alone into the Pacific accompanied by the George Jones hymnal, the same reviewers believe that Don has indeed washed away his old self (a troll) and hopes to be reborn as a new and better person (i.e. a man). ${ }^{56}$ Some, however, feel there is something false or discomfiting about this ending. ${ }^{57}$

Plate 3. Don's baptism in the Pacific Ocean. 'The Mountain King', series 2, episode 12: 46m, 43s.

This unease arises, I argue, because the episode 'stutters' on three mutually reverberating levels. It might initially seem unproductive to try to develop Deleuze's concept of the stutter, as found in his symptomatological analyses, in relation to music. ${ }^{58}$ After all, the whole point of making language stutter-according to one of Deleuze's favoured stutterers, Samuel Beckett—is to bring language closer to the abstract expression of music. Stuttering reproduces the nonspecificity of music: Berg's violin concerto does not say 'this girl died' but rather 'a girl died'. Further, it 'bores holes' in language so that the unsayable can be expressed. Beckett's archetype is the silences in Beethoven's seventh symphony which (non-sonorously) crackle and fizz with

${ }^{55}$ For example John Elia writes: 'at a crucial point in Don's story, when he chooses not to travel with the wealthy, cosmopolitan "nomads" he meets in California and instead returns to his first wife, Anna [...], he is reestablishing himself through his past. Don doesn't really want more freedom, whatever its type. He wants integrity. Only by bringing his past and his present together into some new whole can Don begin to approach happiness': 'Don Draper, On How to Make Oneself (Whole Again)'. In Mad Men and Philosophy: Nothing Is as It Seems (Hoboken, 2010), 173.

56 Again Elia is typical: 'As soon as Don sees Anna, he enters into a confessional mode. He evidently spends a few days reminiscing with her and recovering. The former Mrs. Draper really knows him. He can be truly himself here. Because he isn't running from his past, we see Don more at home, more natural, more grateful and loving, more whole, than we've ever seen him before and will, quite possibly, ever see him again. "The Mountain King" ends with Don entering the ocean, purified by his contact with Anna': 'Don Draper, On How to Make Oneself, 180 .

${ }^{57}$ Will Dean at The Guardian blog felt that the baptism was deliberately too over-the-top to take seriously. Other bloggers were more forthright, for example: 'And then Don goes and stands in the ocean. That, I think, is Weiner's final joke. There is only the appearance of resolution here and only the appearance of religion. It's all sham just like the Desiderata': 'Lies, lies and more lies' on Jules Aimé, Studiously Uncool (28 June 2010).

julessearchforvirtue.blogspot.co.at/2010/06/lies-lies-and-more-lies.html

${ }^{58}$ Of course the digital glitch, one class of which is a literal stutter, has been successfully theorized in Deleuzean terms by many authors as a simultaneous becoming-human of the machine and a becoming-machine of the human, and thus revelatory of the virtual in the way that Deleuze's aesthetics values. See, for example, Steve Goodman, 'Contagious Noise: From Digital Glitches to Audio Viruses', in Jussi Parikka and Tony Sampson (eds), The Spam Book on Viruses, Porn, and other Anomalies from the Dark Side of Digital Culture (New York, 2009), 125-40. 
musical potential energy. ${ }^{59}$ As Deleuze puts it, Beethoven's and Schubert's holes 'in the surface of the sound' allow the 'silence or the audible in itself [to] surge forth'. ${ }^{60}$ But there are other types of 'amusical' glitch that rupture the 'musical' surface - the sound of something new, something different trying to get through. ${ }^{61}$ In 'Cup of Loneliness', it is the cracks in Jones's voice through which this importunate creative force can be 'heard'- the first layer of stuttering in the episode. ${ }^{62}$

In terms of traditional analytic categories, the song is unexceptional. Its sophistication lies in the opposition between protagonist and musical environment. ${ }^{63}$ A slide (probably pedal) steel guitar, and a finger picked acoustic (possibly also steel), bouncing pizzicato double bass, and rudimentary percussion keep the background mood nicely poised between optimistic and relaxed. One might associate the instrumentation and upbeat groove with an evening spent sipping cocktails at a Hawaiian bar. It certainly affords neither the spiritual peace and joy in Christ of the redeemed pilgrims, nor the suffering and loneliness of the protagonist. ${ }^{64}$ But listen carefully to Jones's vocals. Above a standard three-chord accompaniment, Jones sings a diatonic, straight, hymn-like melody. Its arc is aspirational: stretching upwards through arpeggios towards the 'saved from sin' which the protagonist longs for, for instance, only to roll dispiritedly back down again by step. But, it is actually Jones's delivery that is responsible for the oppositional nature of the song. ${ }^{65}$ This is a man who has, as the lyrics say, 'lost all [his] vim', his body beaten down and exhausted. He always limps behind the beat. His voice is continually on the verge of cracking; he strains up towards the higher notes in each phrase, but barely has the energy to sing them. Occasionally at random, he even loses the will to sing at all, merely chanting the words ('To suffer with the savior' in the excerpt heard in the show). ${ }^{66}$ The

\footnotetext{
${ }^{59}$ Just think of the first few bars of the finale, for instance.

${ }^{60}$ Gilles Deleuze, Essays Critical and Clinical [1993], trans. Daniel W. Smith and Michael A. Greco (London, 1998), 173

${ }^{61}$ I am paraphrasing Simon O’Sullivan, 'From Stuttering and Stammering to the Diagram: Deleuze, Bacon and Contemporary Art Practice', Deleuze Studies, 3 (2009), 247-58 at 251. See for example, Laura Marks, 'A Noisy Brush with the Infinite: Noise in Enfolding-Unfolding Aesthetics', (and the following four essays) in Carol Vernalis, Amy Herzog, and John Richardson, The Oxford Handbook of Sound and Image in Digital Media (Oxford, 2013), 101-14. I call the virtual 'amusical' because it is the dimension of the music that can't be directly heard-like the forces in 'Voi che sapete' that produce the sighs, shortness of breath, and bodily convulsions.

62 The scare quotes are because I mean something closer to 'heard-imagined'-for more on this difficult idea, see Daniel Smith, 'Deleuze's Theory of Sensation: Overcoming the Kantian Duality', in Essays on Deleuze, 89-105.

63 Allan F. Moore, Song Means: Analysing and Interpreting Recorded Popular Song (London, 2012), 191.

${ }^{64}$ I use 'afford' in Eric Clarke's sense of the word: of course musical texts are polysemic allowing multiple interpretations, nevertheless some meanings are better served than others, and some have little or no valence at all. Eric Clarke, Ways of Listening: An Ecological Approach to the Perception of Musical Meaning (Oxford, 2005).

65 This is attested by the pedestrian quality of later versions in which the stuttering is absent.

${ }^{66}$ In the verses not heard in the episode, Jones also loses control of his breath on the plosive consonants- the
} 
opposition, then, doesn't occur between figure and ground, vocalist and accompaniment, protagonist and (social) environment; the contradiction exists within the protagonist himself. Despite debilitating exhaustion he is somehow able to stagger on.

Beckett forces language through complex experimental contortions to capture just this ability to 'go on' despite the odds. ${ }^{67}$ But as in Deleuze's understanding of Beckett's stutter, even though 'exhaustion, fatigue, and deflation of energy' threaten to overwhelm Jones's protagonist, the vocal trembling highlights the 'boundless libidinal energy' that eventually allows him to 'rise and continue, ${ }^{68}$

Moreover, the song poses a problem in its new televisual context. In 'Marriage of Figaro', Don and Cherubino merged - they became one other. Here, the music is commenting on what we are witnessing rather than generating Don's specific affective experience in the moment. In this case, it is music's inherent abstraction- $a$ man is exhausted, not just this manthat makes the viewer more likely to attribute this special kind of exhaustion to Don's way of life in general. But then, if Don has chosen to be a 'man' rather than a troll, why does his redemption fail? Why must he fight exhaustion? Why isn't he at the peak of his powers?

In the essay 'He Stuttered', Deleuze argues that 'great writers' don't just make their characters stutter by writing 'he stuttered' or writing out the stutter, rather they craft 'an atmospheric quality, a milieu that acts as the conductor of words - that brings together within itself the quiver, the murmur, the stutter, the tremolo, or the vibrato, and makes the indicated affect reverberate through the words. ${ }^{969}$ The stuttering, amusical elements of the song gain their power to destabilize the viewer's interpretation of the baptism scene because they reverberate so strongly with the second level of stuttering, the episode's milieu—not just in California, but back in New York, where Don's protégé, Peggy, is standing in for him as Creative Director. Peggy's story, actually the end of a season-long arc, anticipates the religious imagery of the final scene. It also stutters by bringing the contradictory elements of her life-her private beliefs with her public work for an advertising firm into relief. Peggy's experiences in this episode express how it feels to live in what Deleuze and Guattari call the 'age of cynicism, accompanied by a

ps and bs, to which early microphones were particularly sensitive — and involuntarily lets out a burst of air pressure that temporarily distorts the sound.

${ }^{67}$ This is encapsulated in the well-known speech at the end of The Unnameable (1952): 'you must go on, I can't go on, you must go on, I'll go on'.

${ }^{68}$ Erika Gaudlitz, 'Stuttering in Beckett as Liminal Expression within the Deleuzian Critical-Clinical Hypothesis', Deleuze Studies, 4 (2010), 183-205 at 195.

${ }^{69}$ Deleuze, Essays Critical and Clinical, 108. 
strange piety'. ${ }^{70}$ Viewers largely absorb this feeling affectively, contributing to the sense that something is wrong with Don's rebirth when it reverberates with the stuttering in the song at the end of the episode.

Deleuze and Guattari's 'cynicism' and 'piety' are structural features of capitalism. Cynicism is capitalism's 'capacity to conjugate and control flows without the introduction of a transcendent or totalising agency'. ${ }^{71}$ Put more simply, people's private beliefs are irrelevant to the operation of capital. ${ }^{72}$ But on the other hand, capitalism needs docile, compliant subjects so it continually 'resuscitates' archaic codes — the accompanying 'strange piety'. Some codes are hangovers from previous modes of social organization, some appear 'spontaneously' in the wake of capital-led deterritorialization, but the main work is done by the state. ${ }^{73}$ In the US, the most successful resuscitation was the concerted effort of big business to align residual Christianity with anti-federal liberalism in the 1930s and 40s, and eventually in the 1950s to have Christianity become the de facto state religion with 'one nation under God' inserted into the patriotic pledge and 'In God we trust' printed on money and stamps. ${ }^{74}$ But this repurposed Christian piety is 'strange' indeed. Walter Benjamin said '[c]apitalism is probably the first instance of a cult that creates guilt, not atonement'. ${ }^{75}$ And the revived US Christianity seems to have been designed to ameliorate the resulting psychological fallout of such a cruel system by teaching its inductees to calmly bear the burden of the sins that they can never redeem.

Consider the George Jones song. Although the first verse is addressed to the Christian pilgrims who have been 'redeemed from sin' and then spiritually reborn 'a new life to begin', emotionally the protagonist identifies with the way the pilgrims felt before their rebirth, when they were in the 'valley'. ${ }^{76}$ Christianity's unique selling-point, as it were, was always that Jesus had paid for the sins of mankind so that any sinner could be forgiven. Yet, in the final verse the

${ }^{70}$ Gilles Deleuze and Félix Guattari, Anti-Oedipus: Capitalism and Schizophrenia [1972], trans. Robert Hurley, Mark Seem, and Helen Lane (Minneapolis, 1983), 225. See also Jason Read, 'The Age of Cynicism: Deleuze and Guattari on the Production of Subjectivity in Capitalism', in Ian Buchanan and Nicholas Thoburn (eds), Deleuze and Politics (Edinburgh, 2008), 139-59 at 147.

${ }^{71}$ Alberto Toscano, 'Axiomatic', in The Deleuze Dictionary, Revised Edition, ed. Adrian Parr (Edinburgh, 2010), 23.

72 The Troll King expresses the very same idea, assuring Peer that living like a troll will not require him to give up his Christian beliefs because belief has nothing to do with action.

${ }^{73}$ Deleuze and Guattari, Anti-Oedipus, 258.

${ }^{74}$ See Kevin Kruse, One Nation Under God: How Corporate America Invented Christian America (New York, 2015).

75 Walter Benjamin, Selected Writings, Vol.1, 1913/1926, ed. Marcus Bullock and Michael W. Jennings (Cambridge, Mass.: Belknap Harvard Press, 1996), 288.

76 The comments on YouTube beneath the song show that many Mad Men viewers went there to listen to the song in its entirety. The second and third verses similarly illustrate the story of the Christian pilgrims. 
protagonist does not seek Jesus's purifying beneficence, but instead 'to suffer with the Savior and when the way is dark and dim, To drink a cup of loneliness with him. ${ }^{77}$ This is precisely why Jones is bodily and mentally exhausted: his sins are never washed away; his pain is permanent. Over the season Peggy suffers in just the same way. Brought up as a good Catholic girl, she has shamed herself and her mother by having an illegitimate child and giving it up for adoption. Her shame is so all-encompassing that she cannot confess her sin and atone, but is instead trapped in a cycle of guilt and self-loathing.

The same cycle is repeated in the workplace. Peggy thinks of herself as a good person, and yet the cynical, decoded application of capital requires she act amorally at work. She channels all her creativity into persuading people to consume products that are unnecessary or may even damage their health-in this episode it's the relatively benign Popsicle. And it is piety_or social subjection— that makes her think it's normal to do this. But cynicism and piety interact in complex and unpredictable ways. Capitalist deterritorialization generates all kinds of new desires, not least for emancipation. ${ }^{78}$ The individual absorbs their belief in freedom and equality into their pious selves. But Peggy's colleagues ridicule her whenever she expresses support for a downtrodden group or progressive cause-working in advertising, they joke, doesn't permit you a conscience. The result is to split the individual. Peggy must somehow convince herself that what she does in the public arena (production and consumption) is separate from her true self. The price, again, is a permanent, ineradicable guilt. ${ }^{79}$

In a wonderfully twisted irony, Peggy's double burden of guilt becomes a source of inspiration within the cynical world of marketing. She realizes something all good ad men and women know: the guilt produced by capitalism can be leveraged to sell things (and produce yet more product-selling guilt in the process). While brainstorming ideas for the Popsicle ad,

\footnotetext{
${ }_{77}$ There is an unfortunate tradition in academia of loftily dismissing country music as nothing more than commercially 'fabricated authenticity'. For example, see Richard Peterson, Creating Country Music: Fabricating Authenticity (Chicago, 1997). Further the special model of Christianity in country music is assumed to be a freefloating, and hence supposedly arbitrary, discourse. Maxine Grossman is typical when she identifies the idea of 'salvific love' in country music as part of a Foucauldian 'regime of truth': 'Jesus, Mama, and the Constraints on Salvific Love in Contemporary Country Music', Journal of the American Academy of Religion, 70 (2002), 83-115, 85. It would perhaps be better to inquire after the material reality that gives rise to these discourses (and their affective expression in music) and how people use the lyrics and music to negotiate that reality in their everyday life.

${ }^{78}$ As Jason Read puts it '[d]esires for freedom and equality circulate along with money and abstract labour as their bothersome after-images.' This isn't a problem in precapitalist societies where 'the distance that separates wealth and poverty is always coded, or over-coded, by symbolic economies of prestige, honour and tradition. Read, 'The Age of Cynicism', 156.

${ }^{79}$ This Nietzschean ressentiment may also directed outwards - towards the Jews, the Muslims, the immigrants, the benefit cheats, the single mums, the social justice warriors, or, just as easily, racists, sexists, the system, capital, the $1 \%$.
} 
Salvatore Romano, a Catholic colleague, reminisces about how his mom would 'break the Popsicles in half, then give it to [him and his siblings] like Jesus at the Last Supper.' Peggy, silencing the (non-Catholic) doubters with the observation that the 'Catholic Church knows how to sell things', decides to run with the idea.

Plate 4. Peggy and Sal's advert for popsicles. 'The Mountain King', series 2, episode 12: 25m, 33s.

The resulting advert, tapping into 'ritual', into 'Christian behaviour, not religion', echoes the Don's quasi-baptism with a quasi-Communion. But just like the hymnal, the advert stutters, unsettling the viewer. In this homage to the kitschier nineteenth-century imitations of $\mathrm{Da}$ Vinci's 'The Last Supper', which added the beatific halo and gaudy colours, the mother's guilt is meant to be assuaged by her ability to dispense the bounty supplied by the transcendent forces of the market. But apart from being 'cheap'—as Cosgrove, one of the doubters puts it— the advert also jars in some initially inexplicable way. In the Da Vinci original, the disciples are all fixated in different ways on Jesus; here the children's focus is on the product itself. The mother is only the conduit for the Christian feelings of community, love, acceptance, and belonging that the tag line 'Take it. Break it. Share it. Love it' appropriates. This parody, then, ends up emphasising the very feedback loop of guilt that Peggy, and much real advertising, attempts to exploit: buying treats for your children to make up for the time you don't spend with them never redeems you in their or your own eyes-it just enables both of you to bear it.

For Deleuze, the third level of stuttering is that of language itself: language stumbles and sputters as the author forces it to express their mental lines of flight. ${ }^{80} \mathrm{I}$ see a parallel to this effect in the way the episode sets up an intertextual correspondence between Don Draper and Peer Gynt, and attempts to feed off the older text's complexities. The series ventriloquizes the philosophical challenges the play opens up, but it moans and judders in the process. The title promises that Peer Gynt will unlock the meaning of the episode in the manner of a complex advert, just as Marriage of Figaro revealed secrets about Don and Betty's marriage. However, we have already seen that the plots of Peer Gynt and the California episodes of Mad Men only share superficial similarities, which ultimately frustrate any attempt to read 'Mountain King' in terms of the play. ${ }^{81}$ This failure to make sense is already a kind of stuttering of the implied advertising form. But, in tandem with the disconcerting images - musicalized or not—of baptism and Communion, it encourages the literarily inclined viewer to seek explanations for Don's situation in the rich scholarly debate about identity formation in Peer Gynt. I briefly follow this path to

\footnotetext{
${ }^{80}$ Ronald Bogue suggests that language itself stutters when expression and content mismatch, rather than there being any isolatable, locally asignifying use of language. See his Deleuze and Guattari (London, 1989), 119-23.

${ }^{81}$ Looking in the comments section of the episode-by-episode guide in The Guardian, for example, almost every commenter has their own opinion about how the episode parallels the play.
} 
demonstrate how the reverberating, multi-level stuttering in Mad Men encourages thought.

Alvhild Dvergsdal has observed that in much of the academic literature on Peer Gynt, which applies equally to the commentary on this episode of Mad Men, 'the interpreter turns out to share the main views on self and self-realization that Peer starts with, especially the view that it is a legitimate and main goal for the single human being to live and work to find his or her inner self, choose it and become him- or herself. ${ }^{82}$ But the play might not be about the misery caused by failing to either be true to oneself (authenticity) or to choose a self and strive to become it (sincerity) after all. Perhaps instead it investigates whether the liberal project of selfactualization is actually the cause of rather than the solution to many modern psychic and social ills. ${ }^{83}$ If this is true, then the Troll King actually lays a cunning trap for Peer since living either like a troll or a man, as the Troll King defines it, curbs his freedom. Living like a troll means simply sating one's animal desires-no freedom at all. Being true to oneself in its modern iteration means exercising the Kantian freedom to follow one's desire to act according to what the rational mind decides is the right thing to do. But as Deleuze and Guattari argue, although the modern subject might have the freedom to choose their own calling, the organization of the drives that generates that calling is determined by the social infrastructure. ${ }^{84}$ And if the drives are predetermined by society, then living according to these drives offers little more freedom than living by one's biological instincts. It turns out, then, that the desire to stay true to oneself is just another, higher-level form of troll-desire.

'The Jet Set' and 'Mountain King' set Don the very same trap-he can choose a life of indolent self-indulgence, or he can be true to the role he has chosen. Don's visit to Anna confirms to him that he also has a permanent, unchanging self (the secret Dick Whitman), that

\footnotetext{
82 Alvhild Dvergsdal, 'To be Oneself: Satan's Ruse', Ibsen Studies, 3 (2003), 32-53 at 33. For a more recent example of this attitude which is still common in Peer Gynt studies, Marit Aalen \& Anders Zachrisson seek to unearth 'structure of desire' in the play: when a person is 'healthy', integrating forces are in the ascendency, whereas when they are 'disturbed', they are in thrall to the 'dynamics of the paranoid-schizoid position'. When unhealthy disintegrating forces dominate, the 'half-developed self even actively opposes 'the constitution of the personality'. In particular 'greed', which is what drives Peer, causes the individual to " "suck dry and devour" the very person [they depend] on to become a fully developed human', leading to the anxiety that one might destroy 'the very source of life'. Marit Aalen \& Anders Zachrisson, 'The Structure of Desire in Peer Gynt's Relationship to Solveig', Ibsen Studies, 13(2013), 130-160 at 134.

83 This is a question Espen Hammer has taken up, arguing that Peer Gynt attempts and reflects upon three different, mutually incompatible versions of modern selfhood. In Hammer's formulation, these are 'oneself without the other' (the radical autonomy of troll-life), Hegelian dialectical 'oneself with the other', and the traumatic absence of 'the other without oneself: Espen Hammer, 'The Question of Selfhood in Ibsen's Peer Gynt, Ibsen Studies, 9 (2009), 34-49.

${ }^{84}$ Gilles Deleuze and Fëlix Guattari, Anti-Oedipus: Capitalism and Schizophrenia, trans. Robert Hurley, Mark Seem and Helen R. Lane (Minneapolis, 1983), 348.
} 
he can somehow hold onto, even when he is role-playing Don Draper back in New York. He cannot see that this presents just as much a temptation to troll-desire as Joy did in 'The Jet Set'. His work for Sterling Cooper routes the productive-desire that flows so abundantly through him into recycling, rebranding, repackaging the same old products to make them appear new thereby enslaving his surfeit of Life to the delirium of capital. Doing this requires Peter Sloterdjik's 'psychological' cynicism (complementing Deleuze and Guattari's 'structural' variety), which makes him Don of the 'borderline melancholics, who can keep their symptoms of depression under control and yet retain the ability to work, whatever might happen'. The time with Anna reassures the cynic Don that the potential for originality, novelty, and life that genuine selfactualization would unlock, still somehow sits masked inside him as his 'true self', Dick Whitman. However, it is precisely the effort necessary to maintain the bifurcated subjectforcing excessive productive-desire down the channels of troll-desire, bending it towards endless reproduction of the same instead of discharging it in genuine creativity — that exacts such a heavy psychic toll on Don. This toll, channelled by Jones's stuttering, is further responsible for making viewers sense something is not right with Don's supposed absolution by his Solveig, Anna.

When the second and third layers of stuttering are gathered together with the first in the final scene, the viewer is presented with a problem. Heard in one way, the George Jones song reflects Don's view of himself as a Randian hero. The personal and social demands others make on him is due to their weakness, and his willingness to sacrifice his individual being (his Dick Whitman) and heroically supress his compassion for others is his strength. ${ }^{85}$ But at the same time, the over-the-top baptismal images resonate with the tasteless popsicle ad, and the viewer to hears it in another way in relation to Peggy. ${ }^{86}$ Debilitating, irremovable guilt is not produced when the self-contained, self-sufficient individual finds themselves burdened and dragged down by weak others, but rather when the connected, dependent individual attempts to sever their ties to friends and family, society and nature. Heard reverberating with the episode's stammering milieu, the song and its faltering voice present the split affective experience of the modern cynic, who projects a calm, blandly optimistic exterior, while nursing a broken, weakened interior, and taking a perverse, pious pride in their ability to carry on. In the resonance of these two levels

\footnotetext{
85 It is a central tenet of Ayn Rand's 'ethical egotism', or 'rational selfishness' - to which Don becomes a convert towards the end of the First Season-that '[a man] will never live for the sake of another man, nor ask another man to live for his'. The Randian then explains the guilt at the heart of capitalism through the doctrine of 'the sanction of the victim', defined by Rand's intellectual heir, Leonard Peikoff, as 'the willingness of the good to suffer at the hands of the evil, to accept the role of sacrificial victim for the "sin" of creating values': 'The Philosophy of Objectivism' Lecture Series (1976), Lecture 8. (Available online at aynrandlexicon.com)

86 Much US entertainment promotes Randian rational egotism as a moral truth, often in unquestioning, uncomplicated manner: see Whiplash (2014) for one of the most extreme music-related examples.
} 
with the third, the shaky parallels with Peer Gynt, further contradictions arise: Don's suffering could be due to his own failure to integrate the disparate fragments of his personality into a unified whole, or it might be the enervating effect of a social infrastructure that reroutes lifereplenishing productive-desire into life-draining troll-desire. If the viewer tends towards the latter view, they may ask what the alternative to the two types of non-freedom offered in Peer Gynt may be. Their question is answered in the final musical moment considered here.

\section{'Lady Lazarus'}

At the beginning of 'Lady Lazarus', Don takes part in a pitch to executives of cologne company Chevalier Blanc. ${ }^{87}$ A young member of the creative team, Ginsberg, explains the basic idea: a horde of screaming teenage girls chase a mop-topped British invasion lookalike around the streets of London. The punchline being, it's not because he's a Beatle, it's because he's wearing Chevalier Blanc. This is the presentation mentioned in the opening of this article, in which the executives, after applauding the presentation, request the ad be accompanied by music that at least sounds like the Beatles, since the Beatles themselves never license their songs for use in commercials. ${ }^{88}$ And it's Don's much younger wife, Megan, whom he asks 'When did music become so important?' It appears he has fallen out of touch with youth and doesn't understand the relationship between psychedelic rock and the counter-culture. ${ }^{89} \mathrm{~A}$ viewer might therefore surmise that he has yet to realize the boundless commercial potential of associating music valued for its strongly anti-commercial sentiment with brands or products. Towards the end of the episode, Megan gives him a copy of the Beatles’ Revolver —released 5 August 1966, just a few months before the episode is set—-to listen to. She suggests he begin with 'Tomorrow Never Knows'.

${ }^{87}$ Mad Men features many real products and many real advertising campaigns from the $60 \mathrm{~s}$-including some brands that have since disappeared-however, Chavalier Blanc is fictional.

88 Throughout the series Mathew Weiner has proved himself adept at self-reflexively incorporating the moneygrubbing aspects of the show's production into its content. What we see in the advertising pitch for Chevalier Blanc mirrors similar discussions AMC executives had with the Beatles about using 'Tomorrow Never Knows'. For reasons of artistic integrity and a wish to preserve their legacy, the Beatles almost never license original recordings of their songs for use in television or film (and never in advertising). (Covers have been used copiously in all commercial settings and Santo \& Johnny's instrumental version of 'Do You Want to Know a Secret' plays over the final credits of 'Hands and Knees' (S4, E10; 26 September 2010).) In something of a coup for Weiner and the show, Mad Men was considered to be of sufficient artistic merit to warrant the use. Nevertheless, AMC still had to pay an eye-watering fee of $\$ 250,000$ for the privilege.

${ }^{89}$ Unfortunately the plot doesn't quite hold together here. The music required by the campaign is more from the 'pop' phase of the Beatles' career, something that Don is already au fait with, having taken Sally to see the famous 1965 Shea Stadium Concert in New York City in the previous season-Sally letting out an appropriate Beatlemania scream when he tells her the news ('Hands and Knees'). 
Just as in 'Mountain King', the title's literary reference points to the sense through which the Beatles song will be heard. In her near-contemporaneous poem 'Lady Lazarus' (1965), Sylvia Plath expresses her disappointment on awaking after each of her many suicide attempts. ${ }^{90}$ This is partly an allusion to the women in Don's orbit, Betty, Sally, and Peggy, who all undergo some important life transformation during the fifth season. It is also about Don. He begins the season in love with his new wife, sneering at Pete Campbell's cheating, letting the younger creatives take the slack in the office, and keeping his drinking under control. By the end, he has lost his connection with Megan, deceitfully prised himself back into the driving seat at work, and finally, at the very end of the season, is on the cusp of returning to his philandering ways. Only now, at 40 , he is a sad middle-aged relic of the Silent Generation, spiralling out of touch with youth. So, although the old Don is being reborn, it is—as Plath apparently felt on being revived each time-as something less than his former self.

Plate 5. Don stares into the abyss. 'Lady Lazarus', series 5, episode 8: 32m, 01s.

In this particular episode, however, the focus is on Megan. Originally Don's secretary, Megan has proved herself to be effortlessly good at the advertising game. Not only is she a gifted copywriter, but she proves a valuable asset in Don's dealings with insecure clients. Nevertheless, she has decided to return to her first love, acting. Don is disappointed when she confesses this to him, but nevertheless arranges for her to quit the company the very next day. Once he has seen her to the elevator, he suddenly seems to remember something and turns around to hit the lift button. When the doors open Don is confronted with an empty lift shaft. Struck by terror, he peers down into the dark abyss. This experience doesn't relate to Megan's departure in any straightforward way. She apparently wishes to escape the emptiness of the advertising world. Stan's wisecrack when he hears about her leaving sums it up: 'You work your ass off for months, bite your nails, for what? Heinz. Baked. Beans.' The advertiser has no connection to the product she is advertising, it is likely to have little value, and so her labour and hence her working life is devoid of meaning. On another level, what advertisers sell is not the sugary, salty, brightly coloured, flour-thickened water that coats the cheap and nutritious haricot bean (often misleadingly referred to as 'tomato sauce'), but the commodity fetish itself: the halo around the product in the stores that the advertising generates. ${ }^{91}$ What the advertisers are selling

\footnotetext{
90 The poem can be easily located online, for example at poetryfoundation.org.

${ }^{91}$ Baked beans are a typical example of the 'plus alpha' strategy of taking a very cheap staple putting it through some industrial process that one cannot achieve at home, and then selling it for a massive markup. The industrial process more often than not, removes all the nutrition and taste from the product, which must then be added back artificially. Margarine - another product featured on the show-is one of the worst offenders in this regard (the transfats produced by the industrial process being toxic), and we enjoy watching the mental contortions the creative team have to go through just to make margarine seem palatable, let alone desirable.
} 
is the void behind the image. ${ }^{92}$

As Guy Debord discusses in The Society of the Spectacle (1967), this fundamental emptiness wasn't confined to those working in the advertising industry. ${ }^{93}$ So completely alienated had the products of labour become that people ended up as passive spectators of their own life, watching themselves trudge through their meaningless and repetitive work, only to spend their leisure time mindlessly consuming products that mirror their empty narcissistic selves back to them. Megan is choosing Debord's solution to this problem: instead of remaining a spectator in a life given over to reproducing more of the same, she is striving to attain the 'free consumption of [her] own time'. ${ }^{94}$ The problem, as Richard Kaplan has argued, is that 'the ideal of a collective revolutionary subject that freely creates society' is implicitly dependent on 'liberal individualism', i.e. the belief in a free subject, independent from the culture and society in which they are embedded..$^{95}$ In subsequent episodes, Megan soon discovers that the autonomous free subject is a fiction and is reduced to taking roles in daytime soaps funded through advertising. Eventually she even begs Don to get her a part in an advert- - her rebirth as an artist ends up saturated with Lady Lazarus regret.

Judging from the interviews he gave in the mid-late 60s, John Lennon held similar liberal individualist views, believing that one's own path could ultimately be found within the self. ${ }^{96}$ For Lennon-just as for Megan, who presumably points Don towards Lennon's song to explain her decision- 'Tomorrow Never Knows' is about tuning out the empty consumerism with which the media fills social space, and instead discovering and learning to listen to the essential self within. Intriguingly, though, George Harrison thought that Lennon didn’t actually understood his own song. ${ }^{97}$ Unlike political crowd-pleasers such as 'Revolution' (1968), 'Power to the

\footnotetext{
${ }^{92}$ Slavoj Žižek gives the example of Coke Zero: it contains no nutrition and is unable to quench thirst; it is pure commodity: The Pervert's Guide to Ideology (dir. Sophie Fiennes, 2012).

93 The Society of the Spectacle, trans. Donald Nicholson-Smith (New York, 1994) is not, as is usually thought, a critique of the 'mass-media'. Debord himself describes the latter as the spectacle's 'most stultifyingly superficial manifestation' (p. 19) and states that the spectacle 'cannot be understood as a product of the technology of the mass dissemination of images' (pp. 12-13).

${ }^{94}$ Guy Debord, Complete Cinematic Works: Scripts, Stills and Documents, ed. Ken Knabb (Edinburgh, 2003), 15.

${ }^{95}$ Richard L. Kaplan, 'Between Mass Society and Revolutionary Praxis: The Contradictions of Guy Debord's Society of the Spectacle', European Journal of Cultural Studies, 15, 457-478.

${ }^{96}$ In an interview given in 1969, for example: 'You're left with yourself all the time, whatever you do-you know, meditation, drugs or anything. But you've got to get down to your own god and your own temple in your head': Man of the Decade (ATV, 30 December 1969).

${ }^{97}$ George Harrison: 'I am not too sure if John actually fully understood what he was saying. He knew he was onto something when he saw those words and turned them into a song. But to have experienced what the lyrics in that song are actually about? I don't know if he fully understood it.' The Beatles Anthology (London, 2000), 210.
} 
People' (1971), and 'Imagine' (1971), which encourage the individual listener to change themselves, 'Tomorrow Never Knows' mounts a challenge to the idea that the human self should be seen as the fundamental object of concern. For Harrison, the lyrics tell us 'what meditation is all about', which is not to discover the true self, but to 'go beyond ... sleeping, waking, and dreaming' in order to lose the self. The aim is to reach a state of disinterested perception in which everything else_including the self_dissolves. Ultimately the self is nothing, neither the world that is perceived, nor the thoughts and desires that western liberalism take to be the self, and it is through a pure openness to experience that consciousness comes closest to realizing this.

In A Thousand Plateaus, Deleuze and Guattari try to imagine how music-which in the romantic tradition, from Beethoven to Beyoncé, is productive of a strong sense of individual subjectivity - might render instead the underlying forces that precede the self. They wanted to know, in other words, how music might produce the state of pre-personal pure sensation sought after in Buddhist meditation. Recall that Deleuze prizes the silence in Beethoven because it allows listeners to hear the febrile tension in the void between the entropic forces of death and the generative (negentropic) forces of life. Sounding music can have a similar effect, Deleuze and Guattari conclude, if it avoids measuring out regular clock time, in which past, present, and future succeed each other in a linear fashion (Chronos), and instead renders audible pure time, in which dynamism is inherited from the past and surges forward into the future (Aion)..$^{8}$ The art music of their contemporaries_-Varèse, Messiaen, Boulez—shifts its focus away from organic individuals to the speeds, intensities, and affective capacities of ever more molecular parts. In these works, the non-pulsed time produced by sound particles whizzing around, colliding, and transforming each other is crucial to making Aion perceptible as the pre-individual (nonrandom) chaos from which new molar organizations emerge. However, Deleuze and Guattari were wrong to assume that pulsed music couldn't perform the same feat. This oversight has been addressed by Kodwo Eshun and others who have demonstrated how pulsed popular music_-particularly the 'sonic fictions' of the Black Atlantic 'rhythmachine' — can also realize Deleuze's aesthetic ambitions. ${ }^{99}$ And I am claiming here that the pulsed 'Tomorrow Never Knows' also liquefies the listener into the non-time of emergence (i.e. of the 'event')-

\footnotetext{
98 Aion, an important concept in Deleuze, is best understood through music. A single note on its own is neutral, but heard as part of a melody all the previous notes and rhythms (and harmonies) give that note its special sense and propel it forward into the future.

${ }^{99}$ Kodwo Eshun, More Brilliant that the Sun: Adventures in Sonic Fiction (London, 1998). One thinks of the missing first beat in reggae or those spaces in James Brown's highly syncopated funk that compels the body to move, of Public Enemy's hectic layering of samples or the accelerated rhythms of jungle that 'spring the sensorium into activity' (p. 71). 'Tomorrow Never Knows' is strongly influenced by (some might say a diluted cultural appropriation of) the Black Atlantic rhythmachine.
} 
something that shouldn't be too surprising given that Deleuze's ecological worldview is so similar to the song's Buddhist 'ecology of emptiness'. ${ }^{100}$

Plate 6. Megan submits to the void. 'Lady Lazarus', series 5, episode 8: 45m, 02s.

Lennon's working title for 'Tomorrow Never Knows' was 'The Void'. The song uses numerous sonic and musical techniques to suggest nowhere and no-when, affordances the audioviewer is more likely to be open to, having understood Megan's reasons for quitting and witnessed Don's experience with the lift shaft, as well as, while the song plays, watching a montage illustrating the emotional barrenness of Peggy's and Pete's lives. The song deals with death and rebirth, falling into and then re-emerging from nothingness-resonating with Plath's 'Lady Lazarus'. Firstly, there is no fade-in, instead the song gradually integrates. ${ }^{101}$ Unusually, only one chord is used throughout, held by an Indian Tamboura. Lennon's use of the mixolydian scale weakens the feeling of resolution when the flattened leading note arrives on the tonic_-on the two syllables of 'dying' in the phrase 'It is not dying', for example. The resultant feeling of going nowhere is intensified in the second and third verses, when Lennon's voice is put through a Leslie speaker so it sounds as though it has no localizable source. Ringo then complements this placelessness with a feeling of timelessness: the hypnotic rhythm (doubled for the full 87 bars by McCartney's high bass) has the second back beat fractionally early (a double semiquaver hit on tom-tom) leaving the fourth beat itself empty. The tambourine (probably played by McCartney) attempts and fails to match Ringo's sticked tom-toms each time, augmenting the temporal squeezing and stretching. ${ }^{102}$ The temporal disorientation is rendered truly disturbing by McCartney's eerie home-made tape loops (the seagull-like sounds interspersed between the lines) and backwards sped-up guitar (not only the extended solo that plays during Pete's pitiful interaction with the woman he can't have, but also as countermelody during the verse), which cut across the established melodic, harmonic and rhythmic patterns. By turns mesmerising and unsettling, the song doesn't reflect back Don's fear of and narcissistic need to escape from the abyss he spied down the lift shaft, it positively embraces it.

Emphasising this point, just before he angrily yanks the needle across the vinyl, Lennon's voice from no-when and nowhere is heard over images of one of Megan's acting exercises-dressed in black and surrounded by shadows, she lies back seemingly submitting to the vacuum in a way

\footnotetext{
100 John Clark, 'On Being None With Nature: Nagarjuna and the Ecology of Emptiness', Capitalism Nature Socialism, 19 (2008), 6-29.

101 There is also no fade out, the song correspondingly disintegrates at the end, something not heard in the episode.

102 Steven Hamelman, 'The Beatles and the Art of the Tambourine', Studies in Popular Culture, 33(2011), 95-116 at 110. This creates smooth (i.e. non-pulsed) space within the conventionally striated space of popular music. Pink Floyd took this idea to its limits in the abstract central sections of songs such as 'Echoes' (1971) and 'Dogs' (1977).
} 
Don dare not.

But if modern existence empties life of meaning, turns everything into an object, arrests the process of history, how can the annihilation of consciousness, the body, and time be a radical, life-affirming act? As many have complained, Buddhism has been sliced up into digestible bite-sized portions, commodified as therapeutic self-help, and sold as a cure-all for modern anxieties. ${ }^{103}$ During this musical moment, however, the episode seems to be steering the viewer towards uncovering the much deeper truths to be found in the religion's philosophy. Contemplating the blankness in the song, the listener asks what the source of the emptiness is. The protagonist, and the listener, lacks individual essence, coherent substantiality, and most crucially a 'self. The meditation presented by the song is not about finding the inner-self, it is about discovering that the ego, like every apparently singular part of nature, is dependent on every other part. ${ }^{104}$ 'Turn[ing] off your mind' and 'lay[ing] down all thoughts' allows the individual's perceptual apparatus to appreciate that, like any other apparently stable object, the self requires a whole web of other human and non-human bodies to maintain it. What is uttered in the lyrics is presented in the temporal (Aionic) flow of the music: the song's protagonist fails to maintain substantial coherence from one moment to the next, and instead continuously emerges anew as part of an ongoing sonic flux. Cleaving to the illusion of the self is destructive because the individual is haunted by its emptiness (existential fear), leading to (troll) desire, the grasping for material possessions, for status and recognition, in a vain attempt to fill the empty space. Letting go of one's attachment to the autonomous ego 'is not dying', and the 'meaning within', the true 'being' that can be 'known', is not that of the 'ego'—as Lennon mistakenly thought—but an appreciation of the interconnection and interpenetration of all things. Grasping the nature of this 'shining void' has the potential to increase one's love and compassion, not just for other people, but for all sentient beings because everything partakes of the same non-substantiality, non-essence, non-identity. 'Love is all, and love is everything'. The universe consists of interconnected interpenetrating flows out of which bodies and selves temporarily and precariously precipitate.

${ }^{103}$ Eske Møllgaard, 'Slavoj Žižek’s Critique of Western Buddhism', Contemporary Buddhism, 9 (2008), 167-180. This is in line with the privatization of religious belief, which was a dominant trend in 1960s, and part of a more general turn towards a 'therapeutic culture' in which self-actualization was the goal. The problem—as Eva Illouz has explained in some depth-is that it has never been clear what a healthy individual might look like, only that an increasing number of behaviours are pathological, usually those that interfere with the subject's productivity within modern corporate management structures.

104 Anna attempts to explain this to Don in more simplistic terms in 'Mountain King': As part of a Tarot reading for Don, she points at 'THE WORLD'. Don is 'part of the world. Air, water, every living thing is connected to [him]'. Anna concludes that it means 'the only thing keeping you from being happy is the belief that you're alone'. 
The first two musical moments differed because in the first the ambient (diegetic) sounds of Mozart's Marriage of Figaro coalesced with the image of Don to generate his momentary affective presence, whereas in the second George Jones's hymnal provided more of an authorial commentary on Don's (and Peggy's) general affective condition. But as a symptomatology they functioned in a similar way. In each, Don's unique personal state, his own symptom, is - through the intercession of music from a slightly or very different social milieuabstracted to a universal condition of consumer capitalism, a virtual potential that may be actualized in multiple ways. In this third scene, something quite different occurs. The music itself doesn't depersonalise Don's concrete affective response; instead the music is a 'sign'. It doesn't present an 'object of recognition', but rather an 'object of "fundamental encounter", violently destabilising Don's adherence to common sense. ${ }^{105}$ It confronts him with the therapy for his condition: he needs to accept that the nothingness that stalks him is an inevitable part of his constructed personhood and that repressing it only feeds his insecurities. But although the music itself doesn't capture Don's own violent reaction, the musical moment as a whole is still diagnostic and — through its resonances with other parts of the episode-universalising. ${ }^{106} \mathrm{It}$ reveals the third and most worrisome symptom: Don craves what is harmful and is terrified by, feels existentially threatened by the cure. It is impossibly painful for the contemporary narcissist to contemplate the dissolution of the self.

Much later, in the very final scene of the series, the beatific smile on Don's face shows us that, at last, he really has understood the importance of music and its ability to capture the impersonal vitality that flows through all things. ${ }^{107}$ Having fled from his new position at advertising giant McCann Ericson, where he had become just one anonymous member of huge team tasked with rescuing the Coca-Cola brand, and suffering yet another identity crisis, Don finds himself at a meditation retreat. After having made a transformative confession, as he did to Anna in Season 2, we again see him enacting a religious ritual, except this time he is voluntarily participating in Buddhist meditation. The scene cuts to McCann Ericson's famous 'I'd Like to Buy the World a Coke' advert from a few months after the scene is set. Don, the genius ad man, has finally understood that the revolutionary idea hiding behind the more common egotistical narcissism of the counter-culture — an idea expressed as well as anywhere in 'Tomorrow Never Knows' — can be used, like Catholicism, to sell things. ${ }^{108}$ He just needed to

\footnotetext{
105 Daniel Smith, 'Deleuze's Theory of Sensation: Overcoming the Kantian Duality', in Essays on Deleure, 89-105 at 90.Smith's quotation: Gilles Deleuze, Difference and Repetition [1968], trans. Paul Patton (New York, 1994), 139.

106 To be clear, I mean 'universal' within consumer capitalism.

107 'Person to Person' (S7, E14; 17 May 2015).

108 The use of a bland identity politics to sell is still going strong in the recent phenomenon of so-called 'woke' advertising or 'identity-washing', in which advertisers target millennials with messages of gender and racial equality.
} 
reduce it to a bland identity politics in order to do so.

Mad Men presents Don as an impersonal site on which the symptoms experienced by consumer capitalism's winners and facilitators converge; it presents these symptoms separately but also gathers them together as a particular illness, something we might name 'Draperism'. ${ }^{109}$ The components of Don's illness are extensively laid out over six seasons. In this essay I have shown how the affective or asignifying qualities of music are used in quite different ways to express three of the most prominent symptoms.

In the first, the nostalgia of Super 8 film and classical music in general, the particular poignancy of the central section of 'Voi che sapete', which becomes a sonic affection 'image' in combination with a close-up of Don's face, and the blurring of diegetic and non-diegetic music, are all artfully combined to generate grief for a certain type of romantic intimacy that ironic detachment now makes impossible. In the second, the protagonist's contradictory subjectivity in 'Cup Of Loneliness' reverberates with the structural and psychological cynicism and 'strange piety' elaborated in the episode to undermine Don's quasi-baptism: he must doggedly persevere and take his satisfaction from his own resourcefulness rather than diluting his self in interactive encounters with others. The third symptom, existential terror, does not occur in the music at all. Instead, a battery of sonic techniques aimed towards loosening any sense that the song's protagonist can be localized in time and space confronts Don with precisely the dissolution of the differentiated self that he so fears. Don's tragedy is that he can't hear what the song is telling him: the strength and vibrancy of any individual body can only be increased when it risks losing itself (becoming other) in continual and varied connections with others.

But there is one way in which the asignifying qualities of the music are acting similarly. In each case, concept and affect do not blend seamlessly together as they do in an advert. Instead, the music draws together a package of linguistic, visual, narrative, and sonic sensations, experienced over the course of the episode in such a way that the viewer senses something isn't right, that there's a problem. Rather than promising the satisfaction a product could never deliver, these moments invite the viewer to speculate about the source of the harmful social forces that operate in a world structured by the logic of advertising. In Deleuze's descriptions of ideal art, the individual or figure dissolves into their milieu. Through reverberations between figure and ground, the viewer is able to perceive the 'figural', the rhythms and intensities

Unsurprisingly, income equality-something that would genuinely improve the lives of the most women and minorities - is routinely ignored.

${ }^{109}$ 'The 'function of the proper name' is one of the 'three fundamental components' of a symptomatology: Smith, 'Deleuze’s “Critique et Clinique” Project', 219. 
through which individuals and milieus are mutually constituted and from which unpredictable becomings and lines of flight emerge. Mad Men never quite achieves this: becoming other is blocked off for Don; any potential for creative difference is rerouted back into repetition of the same. Nevertheless, it is through repetition and resonance that the music in our three scenes goes beyond its ordinary linear, narrative function. The music reverberates with affects from across each episode (not to mention season or series) to render audible the persistent patterns of forces_-'diagrams' or 'machinic assemblages'— that operate to produce consumer capitalism. The music, then, is not tethered to the action in the present, as in typical narrative use, but instead folds together different actualizations of the same underlying diagram of forces. These sonic symptomatologies do not posit 'consumer capitalism' as an overarching cause; instead the force field producing the symptoms is posed as a problem, which remains wholly open-we hear (perceive) that it's there, but can only guess its shape. In this essay I have 'interpreted' (in the Nietzschean-Deleuzean sense outlined above) these symptoms by drawing on critics of consumer society to offer credible explanations. But this does not mean there was a puzzle with a definitive answer to solve: it is by offering the opportunity for this kind of open-ended interpretation that makes these musical moments 'critical'.

Rather than tyrannically instilling certain attitudes and motivations, as 'visceral' political cinema attempts to do, the musical moments in Mad Men elicit in viewers the sense that something is wrong, strange, out of joint; they thereby encourage them to put their motivations, attitudes and behaviours into question. The music-led audiovisual affect here is still doing rather than meaning something. Instead of directly stirring political revolt, however, it encourages groups of people who recognize the symptoms mapped to come together to consider what material action would be necessary to treat them. It interposes a period of communal critical reflection about the causes of the symptoms, an aetiology, and debate on the potential solutions, a therapy-something I have demonstrated here by engaging in that very reflection and debate. The advantage of such an approach to affect is that, unlike the techniques of affective advertising, it is more difficult for the forces of reaction to co-opt. 